PAPER • OPEN ACCESS

\title{
A portable triaxial cell for beamline imaging of rocks under triaxial state of stress
}

To cite this article: Amer Syed et al 2021 Meas. Sci. Technol. 32095403

View the article online for updates and enhancements.

The goal of ECS Sensors Plus, as a one-stop shop journal for sensors, is to advance the fundamental science and understanding of sensors and detection technologies for efficient monitoring and control of industrial processes and the environment, and improving quality of life and human health.

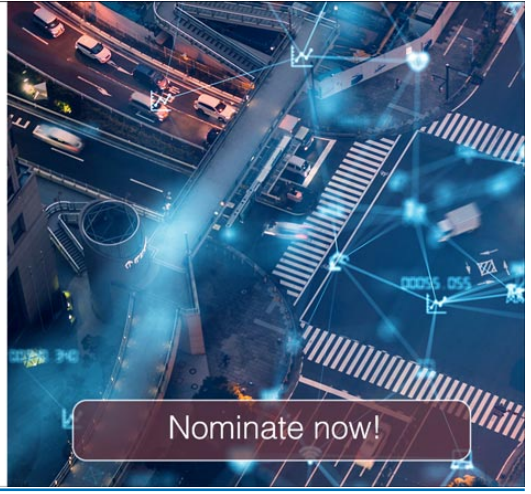




\title{
A portable triaxial cell for beamline imaging of rocks under triaxial state of stress
}

\author{
Amer Syed $^{1, *}\left(\mathbb{D}\right.$, Yukie Tanino ${ }^{1}(\mathbb{D})$, Jacob M LaManna ${ }^{2}$, David L Jacobson ${ }^{2}$, \\ Daniel S Hussey ${ }^{2}$, Eli Baltic ${ }^{2}$ and Genoveva Burca ${ }^{3,4}$ (i) \\ ${ }^{1}$ School of Engineering, University of Aberdeen, Aberdeen AB24 3UE, United Kingdom \\ ${ }^{2}$ Physical Measurement Laboratory, National Institute of Standards and Technology, Gaithersburg, MD, \\ United States of America \\ ${ }^{3}$ STFC, Rutherford Appleton Laboratory, ISIS Facility, Harwell OX11 0QX, United Kingdom \\ ${ }^{4}$ Faculty of Science and Engineering, The University of Manchester, Manchester M13 9PL, \\ United Kingdom \\ E-mail: amer.syed07@alumni.imperial.ac.uk
}

Received 5 January 2021, revised 18 February 2021

Accepted for publication 3 March 2021

Published 1 June 2021

\begin{abstract}
With recent developments in direct imaging techniques using $\mathrm{x}$-ray and neutron imaging, there is an increasing need for efficient test setups to study the mechanical and/or transport behavior of porous rocks. Bespoke designs from commercial suppliers are expensive and often difficult to modify. This paper presents a novel design of a portable triaxial cell for imaging deformation (and a suggested adaptation to introduce fluid transport) through rocks/sand/soil under the triaxial states of stress representative of those encountered in the case of groundwater aquifers or subsurface hydrocarbon reservoirs. The design philosophy and the parameters are detailed so that interested researchers can use this experimental setup as a template to design and modify triaxial cells to suit their own experimental requirements. The design has been used in two imaging beamlines: Imaging and Material Science \& Engineering (IMAT), ISIS facility, Harwell, Oxfordshire, UK, and BT2 of the National Institute of Standards and Technology Center for Neutron Research, Gaithersburg, MD, USA. The mass attenuation coefficients extracted from the 2D radiograms of the triaxial cell were compared with those reported in the literature. Further suggestions for the adaptation of the triaxial cells for studying the mechanics of deformation and fracture in rocks are included.
\end{abstract}

Keywords: neutron imaging, $\mathrm{x}$-ray imaging, rock mechanics, triaxial cell

(Some figures may appear in colour only in the online journal)

\section{Introduction}

Parallel and cone beam imaging techniques are being increasingly-adapted from medical science into other

\footnotetext{
Author to whom any correspondence should be addressed.
}

Original Content from this work may be used under the terms of the Creative Commons Attribution 4.0 licence. Any further distribution of this work must maintain attribution to the author(s) and the title of the work, journal citation and DOI. disciplines to address a wide range of scientific problems [1] including those in metrology [2], complex fluids [3] and specific engineering problems, such as cavitation [4] and nondestructive testing of components such as O-rings [5]. Two such fields that have benefitted from computed tomography is geosciences and geo-engineering, with a notable application being the study of flow through porous rocks [6-11]. Twodimensional (2D) radiograms obtained from neutron imaging can be used to estimate porosity and to identify permeable pathways $[12,13]$, which are often due to an increase in the length of cracks $[14,15]$. Prior to the application of parallel 
or cone beam imaging, observations were primarily derived from bulk measurements or 2D imaging techniques such as scanning electron microscopy (SEM) or transmission electron microscopy (TEM) of thin rock sections. Using these imaging techniques, one can resolve micrometer to submicrometer features of the grain structure and mechanics, but it is not possible to infer any information about three-dimensional (3D) geometrical features, which are significant for defining the mechanical behavior of geomaterials. Furthermore, preparation of specimens, for thin sections, may introduce artifacts that could potentially limit the interpretation of experimental observations. Another important aspect that is neglected in the case of the SEM/TEM is the reference to the in situ stresses (the natural state of rock in the subsurface). Except for a few hard rocks (e.g. granite), most sedimentary rocks, such as sandstone, are compressible and the granular assembly of the rocks undergoes deformation with the application/release of stress.

Rock mass in a subsurface environment is subjected to a triaxial state of stress, which includes:

(a) vertical stress, $\sigma_{\mathrm{v}}$, resulting from the overlying rock mass of density $\rho$, accumulated over a depth of $h$, often termed as the overburden, and with the acceleration due to gravity $g$, is theoretically defined as

$$
\sigma_{\mathrm{v}}=-g \int \rho \mathrm{d} h+\sigma_{\mathrm{t}}
$$

where $\sigma_{\mathrm{t}}$ is the magnitude of tectonic stress, if any, in the region; and

(b) horizontal stresses.

For many subsurface reservoir conditions, the two horizontal stresses are equal for all practical purposes. Hence, the selected shape of the rock sample is cylindrical, wherein the horizontal stress is applied through oil, water or gas on the cylindrical surface and the vertical stress is applied on the flat ends and along the longitudinal axis of the sample. The conventional design of the cells, such as the one proposed by [16], is too large with relatively complex hydraulics, which limit its use for beamline imaging. To address this limitation, the current work discusses the design and application of a novel triaxial cell that requires less space than conventional cells, facilitates easy removal of samples and based on a simple design philosophy that establishes a framework for designs of such triaxial cells that can be easily adapted to suit various requirements in relation to the beamline parameters and the state of stress in the sample.

Typically, the standard triaxial test carried out on rocks (porous as well as non-porous) aims at obtaining three pieces of information: (a) the variation of stress induced in the sample on application of known strain, which, for elastic rocks, provides the basis for the measurement of elastic modulus; (b) Poisson's ratio, to relate the longitudinal compression of the rock sample with radial expansion; and (c) the ultimate compressive stress, which can then be used to obtain the

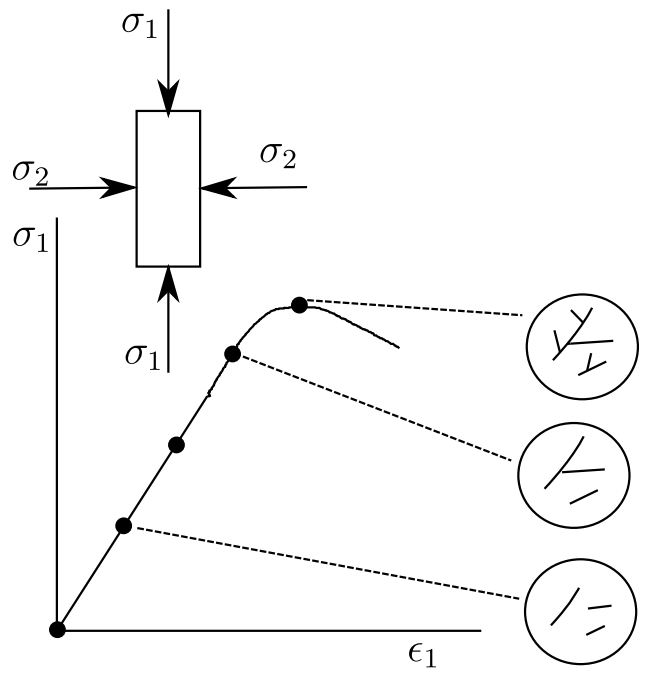

Figure 1. Schematic depicting the development of the crack network in a sample subjected to increasing stress under triaxial conditions. The insets show an idealised microscopic phenomena of initiation, development and coalescing of microcracks with increase in the applied strain.

failure envelope of the rock. While these macroscopic parameters have been measured and have been used to characterize rock, the microscopic observations of grain-grain and grain-binding material interactions including relative deformation and damage have not been directly observed, partly due to technological limitations. Figure 1 depicts a typical output from a triaxial test, normally carried out at a constant strain rate. $\sigma_{1}$ and $\varepsilon_{1}$ are longitudinal stress and strain, $\sigma_{2}$ is the confining stress representing the horizontal stresses. The application of load supplies the strain energy necessary for the initiation and propagation of microcracks which would then further develop resulting in the failure of the material. The current design of the proposed triaxial cell enables the direct observation of deformation at the granular level among other observations (i.e. shear bands) of interest.

\section{Basis of the design and the key parameters}

The subject of mechanical design is multifaceted and is now increasingly multidisciplinary in nature [17]. The approach to the current design derives its principles from radiation physics, material science, mechanical engineering and geological sciences. Often, such multidisciplinary project teams comprise participants less familiar with the design philosophy wherein the identification of information sources and their appropriate use is critical to the success of the designed product [18]. An effective design should always be based on the key parameters that could clearly distinguish a good design from a bad one [19]. There are three key design parameters of the triaxial cell for imaging:

(a) the flux of the particles and their energy;

(b) the maximum load intended to be applied on the rock; and

(c) the design or safety factor. 
For most beamlines, the flux is fixed and the attenuation of the particles needs to be minimized. In some cases, the thickness of the material through which the neutron beam/x-rays have to pass cannot be controlled, which warrants the application of additional techniques, such as combining stacks of multiple energies [20]. For the current cell design, the thickness of the cell wall and the diameter of the sample dictate the attenuation of particles and the maximum stress that can be applied based on the design considerations. The trade-off for item (b) is prescribed by the constraints imposed by items (a) and (c).

\subsection{Constraints from the beamline facilities}

$\mathrm{X}$-ray and neutron imaging beamlines are widely used in the field of material characterization and more recently of geomaterials. X-rays and neutrons provide complementary information, thus informing the nature of the material investigated [21]. While x-rays, especially from synchrotron sources, enable images of higher resolution to be captured, neutrons, on the other hand, are suitable for probing lighter elements such as hydrogen and can be used to investigate thicker sample materials. This properties of neutrons help the imaging of geomaterials containing hydrogen-rich fluids, such as water and oil. Furthermore, $\mathrm{x}$-ray imaging of rock-fluid interactions requires the fluid to be doped with potassium iodide, especially if multiple fluids are present in the pore spaces, which can be avoided if neutron imaging is used.

With minor variations, imaging experiments consist of acquisition of $2 \mathrm{D}$ radiograms of the sample placed on a rotating table in the beamline. The attenuated radiation $(I)$ can be computed using the sample of density, $\rho$, and thickness, $x$, the mass-attenuation coefficient $\mu / \rho$ ( $\mu$ is the linear attenuation coefficient) and the incident radiation $\left(I_{\mathrm{o}}\right)$ as [22]

$$
I=I_{\mathrm{o}} \exp [-(\mu / \rho) \rho x] .
$$

When the sample placed in the beamline is made of $n$ different elements, equation (2) can be modified as

$$
\ln \left[\frac{I}{I_{\mathrm{o}}}\right]=-\sum_{i}^{n}\left(\frac{\mu}{\rho}\right)_{i} \rho_{i} x_{i} .
$$

The attenuation of four elements will be of interest in the current context of imaging rocks enclosed in a triaxial cell: aluminum in the various components of the triaxial cell, iron in the fixtures (e.g. bolts), silicon in the grains of rock and carbon if the pore space in rocks is saturated with organic materials such as hydrocarbons. For the purposes of comparison, the mass attenuation coefficient along with the specific densities are given in table 1 and will be used in the analysis of data later. It is to be noted that for the beamlines discussed here, the wavelength, $\lambda$ is centered around $0.18 \mathrm{~nm}$ for BT2, the maximum flux at IMAT is around $0.26 \mathrm{~nm}$ and the coefficients reported in [22] correspond to approximately $\lambda=0.018 \mathrm{~nm}$. For the design of $\mathrm{x}$-ray and neutron transparent triaxial cells, it is vital to assess the mass attenuation coefficient of the system. Commercially available triaxial cells are either made of carbon fiber composites [10] or aluminum, with the latter being the cheaper alternative. Commercially available core holders
Table 1. Selected properties of carbon, aluminium, silicon and iron for neutrons $(\lambda=1.08 \AA)$ and x-ray $(90 \mathrm{keV})$.

\begin{tabular}{lccc}
\hline Element & $\begin{array}{c}\mu / \rho \text { neutron } \\
\left(\mathrm{cm}^{2} \mathrm{~g}^{-1}\right)[22]\end{array}$ & $\begin{array}{c}\mu / \rho \text { x-ray } \\
\left(\mathrm{cm}^{2} \mathrm{~g}^{-1}\right)[23]^{\mathrm{a}}\end{array}$ & $\begin{array}{c}\rho \\
\left(\mathrm{g} \mathrm{cm}^{-3}\right)[23]\end{array}$ \\
\hline Aluminium & 0.04 & 0.186 & 2.699 \\
Iron & 0.2 & 0.484 & 7.874 \\
Silicon & 0.045 & 0.203 & 2.33 \\
Carbon & 0.3 & 0.156 & 1.7 \\
\hline
\end{tabular}

${ }^{\mathrm{a}}$ Interpolated from the source data.

are used to study pore-scale flow and non-localized deformation. An important aspect is that although carbon can be readily used as a sample holder for neutron imaging, carbon fiber composites are unsuitable due to the high hydrogen content of the epoxy resin used in the manufacture. A simple design of a X-ray transparent aluminum cell was detailed by Fussels et al [24]. Aluminum has a few distinct advantages over carbon in addition to favorable mass attenuation coefficients for neutrons. Aluminum alloys are cheaper, easy to machine and readily recyclable after their use, thus making them a sustainable option.

\subsection{Constraints imposed by the rocks to be tested}

Most rocks used in the construction industry, as well as those investigated for oil and gas, such as sandstones, are consolidated and exhibit near-perfect elastic behavior with a brittle mode of fracture. However, with the interest in non-conventional hydrocarbon recovery, rocks with complex mechanical behavior, such as shales, are being studied with interest. Broadly, two types of minerals affect the degree of brittleness within the rocks: (a) quartz imparts brittleness in the rocks resulting in small elastic strain when loaded in compression prior to failure; and (b) clay imparts ductility, resulting in larger strains. Therefore, rocks containing these two minerals exhibit the behavior of dominating minerals, i.e. sandstones are brittle as the dominating mineral is quartz, whereas the mechanical behavior of shale depends on whether quartz or clay is the dominant mineral. Hence, the cell design needs to take into account the possible failure of the rocks that are intended to be tested.

\subsection{Factor of safety}

The factor of safety $(\mathrm{FoS})$ is included to ensure the equipment is safely operated. The FoS is often calculated as a ratio of the ultimate stress induced in the mechanical component and the working stress. However, other factors such as the presence of stress concentrations, exposure to extreme environments (temperature, pressure, corrosion, etc), frequency of maintenance or the operational setting are important factors to consider while designing the equipment. As the current triaxial cell is designed to be used in beamlines, the following aspects were considered while assigning an FoS: (a) the uncertainty in the strength of the rock; (b) the environment of the beamline, which is often confined spaces with a range of expensive and 
sensitive equipment; and (c) the requirement for the triaxial cell to be portable and transparent to the beamline.

The FoS for the current design is based on the ratio of the maximum stress induced in the cylindrical component (the main body) of the triaxial cell to the ultimate compressive strength of the rock. The uncertainty in the denominator is to be taken into consideration when deciding on the FoS. This design was used for experimentation at two beamlines: (a) IMAT at ISIS, a UK Science and Technology Facilities Council (STFC) facility in Harwell, Oxfordshire, UK; and (b) the National Institute of Standards and Technology (NIST) Center for Neutron Research (NCNR), a US government facility in Gaithersburg, MD, USA. Details of the use and snapshots of the results are discussed in section 6 .

\section{Experimental test setup}

Figure 2 shows the complete setup including the ancillary equipment. The load is applied via a $100 \mathrm{~kg}-\mathrm{f}(10 \mathrm{t})$ piston jack, which in this case was low profile 'pad jack' type (RLS 100), supplied by Powerteam ${ }^{5}$. This portable piston cylinder could also be a low height hydraulic cylinder (RCS 101) offered by Enerpac. The selection would be based on the required load to achieve the desired deformation and the budget to build the test setup. The piston is connected to a manual hydraulic pump through a 316 stainless steel seamless $3.175 \mathrm{~mm}$ (one-eighth inch) outer diameter and $0.7112 \mathrm{~mm}(0.028 \mathrm{inch})$ thick tubing supplied by Swagelok (part number: SS-T1-S-020-6ME) with a maximum working pressure of $58.605 \mathrm{MPa}$ (8500 psi). A key design aspect is the ability to isolate the pressure line after exerting required $\sigma_{\max }$ and $\sigma_{\min }$ on the rock sample. A twoway valve is connected close to the piston (316 stainless-steel quarter turn instrument plug valve with $3.175 \mathrm{~mm}$ (one-eighth inch) Swagelok tube fitting $0.1 \mathrm{Cv}$-part number SS-2P4T and working pressure of $20.6 \mathrm{MPa}$ ) and next to the valve is a pressure gauge $(63 \mathrm{~mm}$ pressure gauge with lower fitting and dual scale 0 psi-3000 psi and 0 bar-200 bar supplied by Omega Engineering UK, part number PGM-63 L-3000PSI/200BAR) and another two-way valve (same as previous). In order to change the $\sigma_{\max }$ on the rock, the two valves are opened and using the manual pump (Enerpac P141, single speed hydraulic pump). Once the required $\sigma_{\mathrm{v}}$ is reached, the valve closest to the pump is closed, while the pressure in the gauge is monitored to ensure the $\sigma_{\mathrm{v}}$ on the rock is stable. Valve $\mathrm{v}_{1}$ is closed and valve $v_{2}$ is opened to reduce the pressure in the line before disconnecting the compression fitting. Once isolated, the cell will retain hydraulic pressure while a complete set of radiograms is acquired. The design of the system eliminates the need for flexible tubing that may otherwise be required to ensure smooth rotation of the cell, while 2D radiograms are acquired for different angular rotations of the triaxial cell.

\footnotetext{
${ }^{5}$ Certain trade names and company products are mentioned in the text or identified in an illustration in order to adequately specify the experimental procedure and equipment used. In no case does such identification imply recommendation or endorsement by the NIST, nor does it imply that the products are necessarily the best available for the purpose.
}

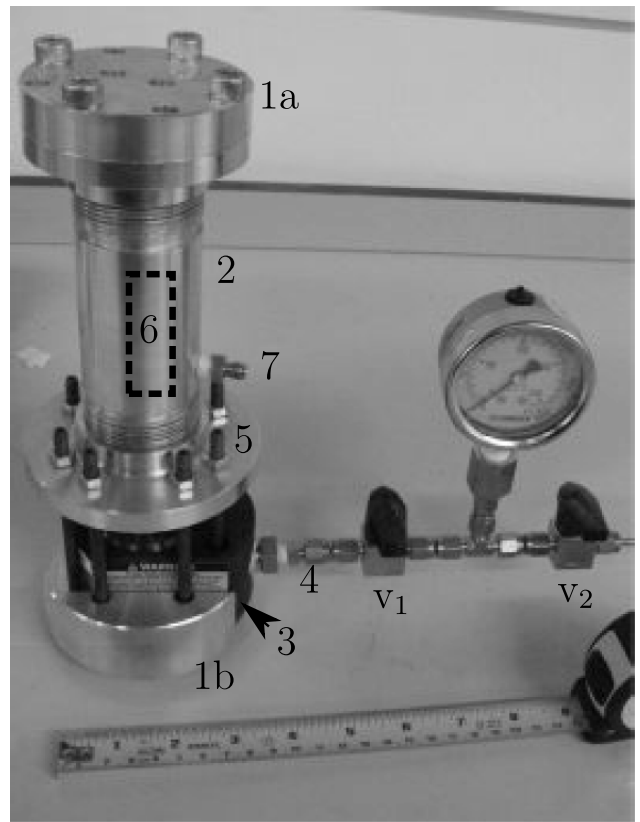

Figure 2. Experimental setup: (1a) and (b): platens; (2) body of the cell to hold sample rock sample; (3) loading ram $\left(\sigma_{1}\right)$; (4) hydraulic oil supply for the ram; (5) high tensile strength bolts; (6) rock sample; $(7)$ confining pressure $\left(\sigma_{3}\right)$ port.

Figure 3 shows a cross-section of the triaxial cell. It can be observed that the rock sample is supported by a sleeve, which ideally should be a fully fluorinated polymer. However, partially fluorinated polymers or, for instance, Viton could be used, especially if the fluids are likely to react with the sleeve. Another option that has been used in the past, although not as flexible as Viton, is heat shrink tubing. The top platen is fixed and is secured by four to eight bolts. The lower platen can move and transfer load from the hydraulic jack to the rock sample. It also has fluid ports for injecting fluids into the rock sample. It is common to have a distribution network of channels to the upstream platen to ensure the fluid is injected uniformly into the rock sample rather than two points but is omitted from the current design as it will reduce the area in contact with the rock sample and hence will not be able to apply load uniformly to the rock sample. The following sections detail the design of each of the components shown in figure 3 .

\section{Design of various components of the triaxial cell}

\subsection{Main body}

The main body is the pressure-bearing component of the cell. It can be designed as a thick or thin walled cylinder, which in turn depends on the intensity of the imaging beam. The maximum attenuation can be calculated by knowing the exact composition of the aluminum alloy used, the chemical composition of the rock and the fluid in the pore space. Using mass attenuation data, the thickness of the main body spanning the length of the sample being imaged for acceptable attenuation of the beam can be determined. 

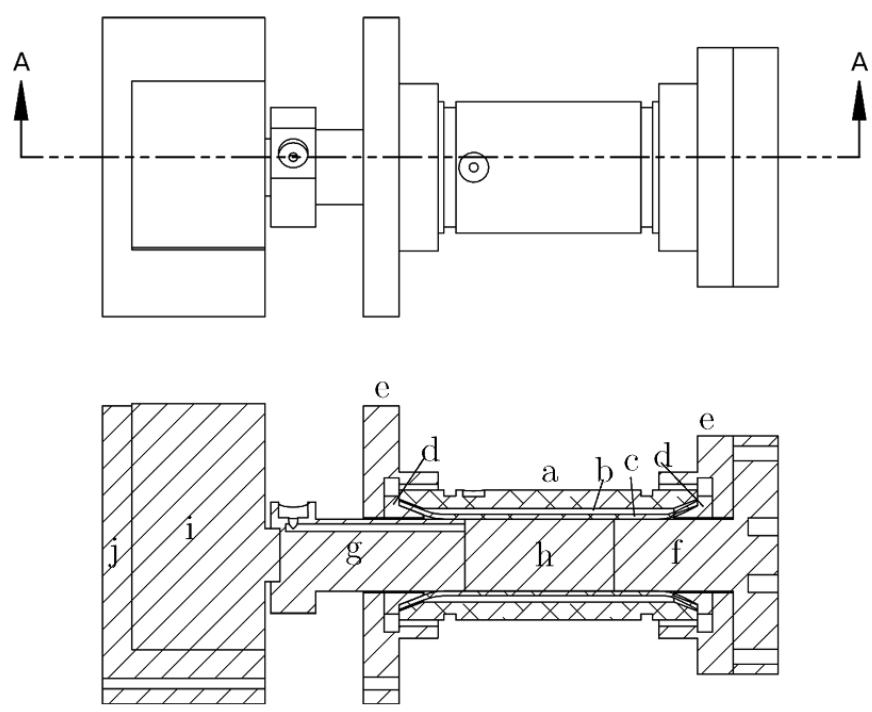

$25 \mathrm{~mm}$

Figure 3. Triaxial cell: (a) main body; (b) space for confining fluid; (c) rubber sleeve; (d) collar; (e) end cap; (f) fixed platen; (g) moving platen (loading side); (h) rock sample; (i) hydraulic jack; (j) housing for the hydraulic jack.

The material selected for the cell is aluminum 6082-T6 alloy, as it has the highest strength (nearly $240 \mathrm{MPa}-250$ MPa of proof strength and $300 \mathrm{MPa}$ of tensile strength) among 6000 alloys. Furthermore, the 6082 alloy has good corrosion resistance and is commonly used in applications involving stress-bearing components. One limitation of 6082 is the high manganese content, as $\mathrm{Mn}$ is strongly activated with neutrons releasing a strong beta radiation, making sample handling immediately after imaging quite challenging. To overcome this issue, aluminum 6061-T6 can be used. It is also noted that if strength is an absolute requirementfor instance, when testing extremely hard rocks-7075 alloy may be an option but would radiate a strong beta radiation field due to manganese. One noteworthy aspect is that the inclusion of other metals in the chosen alloy, for instance cobalt, would pose significant limitations in handling after the termination of the experiment due to the degree of activation.

The body of the triaxial cell is tubular with inside edges chamfered to house the collar that provides a seal with the rubber sleeve which in turn holds the rock sample in place (figure 3). The details of the other components are discussed later. A fluid entry and exit port that houses a $3.175 \mathrm{~mm}$ (oneeighth inch) National Pipe Thread (NPT) fitting is placed close to one end of the cell to facilitate the hydraulic pressure for confining stress $\left(\sigma_{2}\right)$. The hole is positioned to ensure that it is sufficiently away from the rock sample (as shown in figure 4) for two reasons: (a) it is designed to house a $3.175 \mathrm{~mm}$ (oneeighth inch) NPT stainless-steel male to $3.175 \mathrm{~mm}$ (one-eighth inch) female compression fitting (of Swagelok type), which

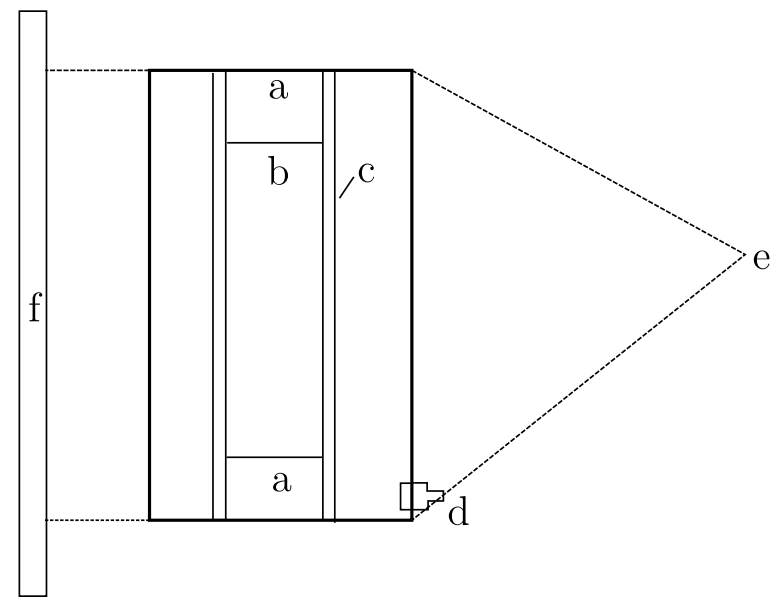

Figure 4. Triaxial cell with location of the NPT fitting for confining fluid: (a) platens; (b) rock sample; (c) rubber sleeve; (d) $3.175 \mathrm{~mm}$ (one-eighth inch) NPT fitting; (e) source; (f) detector.

will have higher attenuation and, if near the rock sample, it may affect the quality of the images acquired; and (b) if the images are truncated to contain only the rock sample and tubular part of the cell, the 3D reconstructions from those 2D radiograms are faster. The ends have a $46 \mathrm{~mm} \times 2 \mathrm{~mm}$ threads to house the end caps.

The critical load bearing part of the experimental test setup is the main body as it is subjected to the confining pressure of the fluid as well as stress resulting from the dilation of the sample during testing. Therefore, finite element analysis of the load bearing main body was undertaken. Apart from testing the structural integrity, the finite element analysis is expected to inform the FoS in the design.

Figure 5(a) depicts the 3D model of the main body created in SolidWorks software along with the imposed boundary conditions. The flat sides of the top and bottom of the cell were assumed to be fixed as these are held in place with near-zero allowable displacement during the test. In the real setup, the main body of the triaxial cell will also be subjected to axial tension due to the tightening of the bolts (shown by the number 5 in figure 2). The axial stress will, in fact, increase the burst pressure. However, for the current finite element modeling exercise, the axial stress is ignored, which results in a lower burst pressure and therefore a higher FoS. The threaded hole where the $3.175 \mathrm{~mm}$ (one-eighth inch) NPT to Swagelok fitting for confining pressure is housed (number 7 in figure 2) is fixed as the integrity of the fixture is ensured by selecting the correct fitting and appropriate depth of the thread. A uniform pressure was applied on the internal cylindrical surface, reflecting the application of confining pressure $\sigma_{3}$. The internal pressure applied on the main body of the cell is one of the design parameters and can be used to optimize the cell design, especially in terms of its thickness. Also note that the thickness of the cell/enclosure is an important parameter for synchrotron and non-synchrotron-based x-ray 


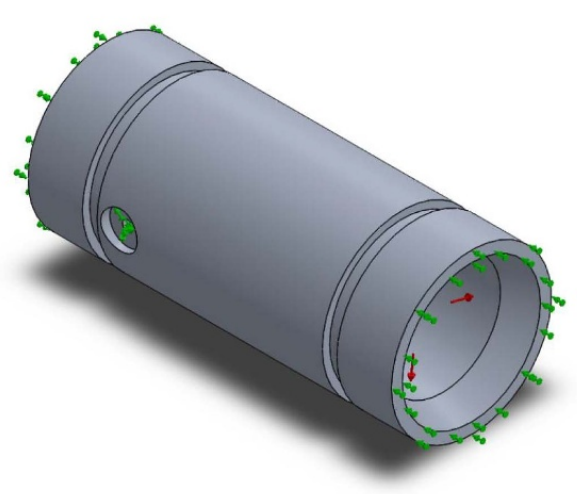

(a)

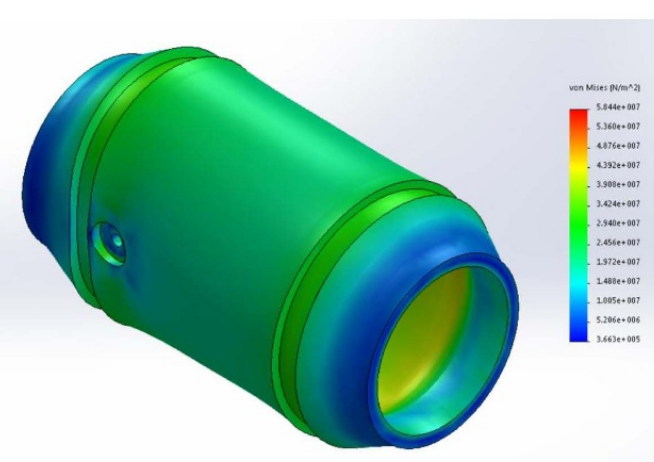

(c)

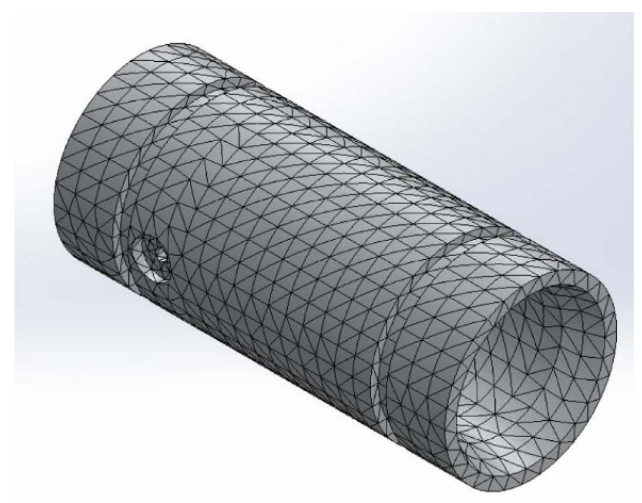

(b)

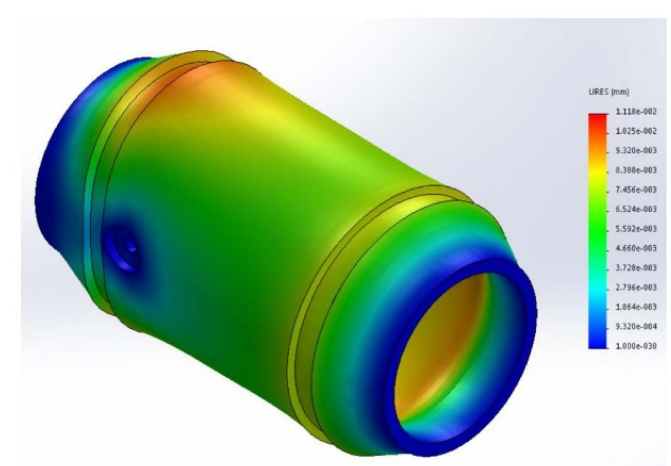

(d)

Figure 5. Triaxial cell with (a) boundary conditions, (b) finite element mesh, (c) von Mises stress and (d) deformation under internal pressure of $10 \mathrm{MPa}$.

sources for imaging. However, the design is easily adaptable, as only the thickness of the main body needs to be altered to suit the energy in the imaging beamlines and phenomena of interest. In the current study, the cell was designed for an internal pressure of $10 \mathrm{MPa}$.

Figure 5(b) depicts the finite element mesh. To enable discretization of all the features in the triaxial cell body, a free mesh was chosen and was optimized for convergence of displacement and stress.

Figure 5(c) shows the von Mises stress distribution within the main body of the triaxial cell and it can be noted that the maximum stress is near the hole that houses the $3.175 \mathrm{~mm}$ (one-eighth inch) NPT fitting, indicating the effects of concentration of stress due to the removal of material with slightly reduced thickness. The maximum stress induced due to the confining stress of $10 \mathrm{MPa}$ was found to be $58 \mathrm{MPa}$. The FoS for the current design is 4.31 , for a conservative yield strength of 6082 alloy as $250 \mathrm{MPa}$. Note that the thread recesses at both ends are chamfered and therefore do not contribute any stress to those areas.

Figure 5(d) shows the resultant solid displacement within the main body of the triaxial cell due to the applied internal pressure of $10 \mathrm{MPa}$. The shape of the distorted body is similar to other cylindrical vessels subjected to internal pressure.

\subsection{Seal for the triaxial cell}

The rock is held in place with a rubber sleeve (parts (h) and (c) respectively in figure 3). A SolidWorks model of the taper is shown in figure 6. The taper on the conical section of the collar is identical to that on the cell main body, which allows positioning of the sleeve so that it is compressed between the main body and the collar providing a surface seal. Note that the edges of the conical part must not be sharp to avoid any possible damage to the rubber sleeve. A fillet was applied to the edges to make it smooth. The taper angle must be selected to avoid sharp corners and retain the ability to slide the rubber sleeve on the collar for the assembly that provides the seal for the confining pressure. The sliding action of the conical element also enables the process of gradually settling up of rubber to provide a seal, as described in section 5 below.

The end cap (figure 6) is designed to hold the collar and the sleeve in place. The end caps are threaded and are designed to match the thread on the body. In the current design $46 \mathrm{~mm} \times 2 \mathrm{~mm}$ threads are machined on both of the end caps and on the main body of the cell. As shown in figure 3, the end cap thread on the main body and during the turning movement push the collar firmly into the main body, thereby forming a seal for the confining fluid (space is indicated by b in figure 3 ). The end caps also have eight equispaced holes at angle $45^{\circ}$ 


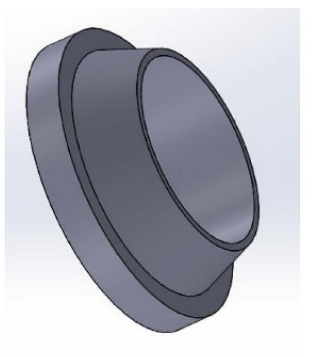

(a)

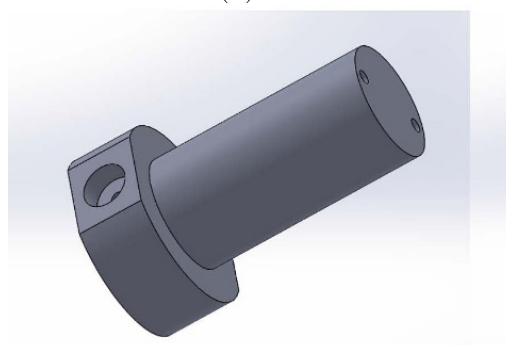

(c)

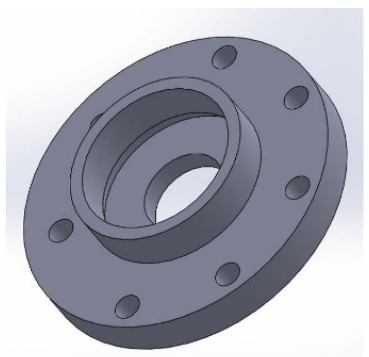

(b)

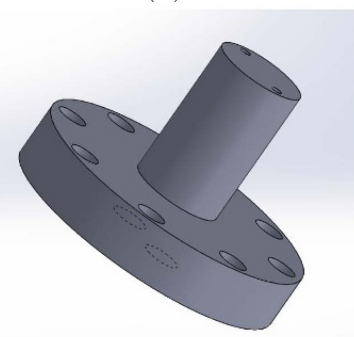

(d)
Figure 6. Parts of the triaxial cell: (a) collars that provide a seal; (b) endcaps; platens for (c) loading and (d) fixed side.

threaded to M6 to secure the platen (discussed in section 4.3 below).

\subsection{Platens}

Platens (plate-like structures with protrusions) have two functions in this cell:

(a) to impart load or to apply displacement boundary conditions; and

(b) to facilitate the flow of fluids through the rock sample (design was incorporated in the current setup but was not used in the demonstration).

There are two platens for the triaxial cell. First, there is a floating platen at the loading side of the cell (figures 3 and 6). It consists of a single cylindrical member with an extension at the end, primarily designed to limit the possible displacement, in case needed, and to enable the flow of fluids into and out of the rock. The extended portion has two ports each of depth $12 \mathrm{~mm}$ to house a $3.175 \mathrm{~mm}$ (one-eighth inch) NPT male connector to compression fitting (of Swagelok type). The length of the platen depends on the rock sample and estimated compression of the sample before failure. Two holes of diameter $3 \mathrm{~mm}$ run parallel to the longitudinal axis of the platen which can be used to inject fluids into the rock sample. The spacing between the holes can also be varied to suite specific experimental requirements. For the current design, the spacing between the ports was maximized and hence was set to $19 \mathrm{~mm}$.

Figure 6 shows the fixed side platen. The cylindrical part of the platen is identical to the loading side platen but the cylindrical part ends in a flange, which is used to secure the platen to the end cap (figure 3 ). The flange has eight clear holes at $45^{\circ}$ as well to match the end cap. Depending on the load, only four bolts may be sufficient to secure the platens.

\subsection{Plumbing}

The plumbing of cells with ancillary equipment was carried out with $3.175 \mathrm{~mm}$ (one-eighth inch) stainless-steel tubing supplied by Swagelok. The fittings were of 316 stainless steel and are rated in accordance with the ASME Code for Pressure Piping B31.3. The pressure ratings for the fittings used are: maximum pressure of $68.9 \mathrm{MPa}$ (male) and 44.7 $\mathrm{MPa}$ (female).

\subsection{Loading mechanism}

The load is applied using an RLS 100 hydraulic loading jack supplied by Powerteam. The maximum load that can be applied using an RLS 100 is $89000 \mathrm{~N}$ (10 t). It is relatively lightweight, making the test setup very portable. It is housed in aluminum housing (figure 2). The RLS 100 has two holes which can be matched with the bottom platen using through bolts through the housing; spacing between the loading side end cap and the piston of RLS100 can be maintained. Before securing the bolts on the loading side end cap, it is advisable to ensure that there is enough space for the piston to travel so that the rock can be compressed to failure. A two-way valve is placed inline and can be used to isolate the cell once the desired axial load is applied to the rock sample. This isolation enables easy rotation of the cell along the longitudinal axis and hence makes it a convenient setup for use in fixed-source (x-ray or neutron) 3D tomography. A similar arrangement can also be used for confining stress $\left(\sigma_{2}\right)$.

\subsection{Bill of materials}

Table 2 details the itemized cost (in British Pound Sterling) of the components used in the triaxial cell setup. It is to be noted that the prices include value-added tax (UK and EU, where applicable) and educational discounts (variable as it is in accordance with commercial negotiations between the university and individual suppliers) offered by suppliers to the University of Aberdeen. The total cost does not include the cost of manufacturing the equipment at the University of Aberdeen's workshop and subsequent modifications undertaken at the workshops at NIST and IMAT. Furthermore, the materials were procured at different times and therefore the costs in table 2 should be taken with caution.

\subsection{Errors and uncertainty}

The accuracy of the vertical load and confining stress will depend on the accuracy with which the pressure gauge can be read. In the case of the PGM-63 L-3000PSI/200BAR pressure gauge used in the current setup, the accuracy of the instrument is $1.6 \%$ of span (200 bar). Parallax error is another source of error in the application of the load on the sample. The lowest count in this pressure gauge is 10 bar and hence the uncertainty in the measurement of applied pressure would be 10 bar. For experiments that require a high degree of precision in the application of loads, it is recommended that digital pressure transducers be used to monitor the pressure. Use of a pressure controller for the application of both confining stress 
Table 2. Bill of materials for the triaxial cell set up. The unit and total cost stated are in British Pound Sterling.

\begin{tabular}{|c|c|c|c|}
\hline Component & Quantity & Unit cost & Total cost \\
\hline Power Team RLS100 Cylinder & 1 & 204.41 & 204.41 \\
\hline $1 / 16$ in $\mathrm{OD} \times 0.020$ in WT $316 / 316$ : Tubing $(\mathrm{SS}-\mathrm{T} 1-\mathrm{S}-020-\mathrm{ME})$ & 6 & 10.69 & 64.13 \\
\hline $\begin{array}{l}\text { SS Quarter-Turn Instrument Plug Valve, } 3.175 \text { mm (1/8 in) Swagelok Tube Fitting, } 0.10 \\
\text { Cv (SS-2PT4T) }\end{array}$ & 2 & 69.19 & 138.38 \\
\hline $\begin{array}{l}63 \mathrm{~mm} \text { pressure gauge with lower fitting and dual scale } 0 \text { to } 3000 \text { psi and } 0 \text { to } 200 \mathrm{Bar} \\
\text { (PGM-63 L-3000PSI/200BAR) }\end{array}$ & 1 & 70.88 & 70.88 \\
\hline Enerpac Hhand pump & 1 & 276.73 & 276.73 \\
\hline Viton sleeve $(1 \mathrm{~m})$ & 1 & 408.75 & 408.75 \\
\hline Minature Quick-Connect Body, 0.05 Cv in Swagelok tube fitting (SS-QM2-B-200SS) & 1 & 56.65 & 56.65 \\
\hline Swagelok Tube fitting Union Tee 3.175 mm (1/8 in) Tube OD (SS-200-3-SS) & 2 & 25.94 & 51.88 \\
\hline SS Swagelok Tube Fitting, Reducer, $1 / 16$ in × 3.175 mm (1/8 in) Tube OD (SS-100-R-2) & 1 & 14.18 & 14.18 \\
\hline $\begin{array}{l}\text { SS Swagelok Tube Fitting, Male Connector, } 3.175 \mathrm{~mm}(1 / 8 \mathrm{in}) \text { Tube OD } \times 3.175 \mathrm{~mm}(1 / 8 \\
\text { in) Male NPT(SS-200-1-2) }\end{array}$ & 1 & 7.98 & 7.98 \\
\hline Aluminium stock & 1 & 75.00 & 75.00 \\
\hline Total & & & 1375.69 \\
\hline
\end{tabular}

and axial load could also be a viable option, especially if pressure-sensitive rocks are to be tested.

\section{Discussion on the design and operation}

The design of this triaxial cell is simple and the components are easy to manufacture in a standard machine shop and can be assembled with relative ease. The key aspect of the cell is the formation of the seal for the confining fluid between the collar and the body of the cell. The following is a sequence adapted for pressure testing of the cell and is based on the stress relaxation of the Viton elastomer sleeve.

(a) A solid steel cylinder (diameter 25.4 and $70 \mathrm{~mm}$ in length) was introduced into the main body and the end cap was gently tightened to be finger tight. Nitrogen was then injected into the confining pressure space to maintain a pressure of $0.7 \mathrm{MPa}(\approx 100 \mathrm{psi})$.

(b) The cell was isolated by closing the valve next to the confining pressure port. If the pressure had been reduced over a short period of time $(\approx 0.03 \mathrm{MPa}$ over $5 \mathrm{~min})$, then it was very likely due to a leak somewhere, which was identified and the end caps were tightened until the leak stopped. Leaking nitrogen from the triaxial cell can be detected by pouring a few drops of soapy water onto the threaded portions of the main body of the cell (which was found to be the most common pathway for the leak) and at locations where different parts have been joined.

(c) The triaxial cell was then left for approximately $24 \mathrm{~h}$ with the pressure monitored with time. If the drop in pressure is in excess of $0.07 \mathrm{MPa}(10 \%)$ then the leak was identified through the use of soapy water and in the absence of observable leaks the end caps were to be tightened as the drop in pressure was attributed to very slow release of gas through the end cap assembly.

(d) Once the pressure is sustained over $24 \mathrm{~h}$, fresh gas from source was injected into the confining pressure chamber to increase the pressure to $1.5 \mathrm{MPa}$ and the aforementioned process is repeated.

The intention of this exercise is to obtain a permanent shape of the Viton sleeve by incremental application of pressure. The steps suggested above for the setting of sleeve are purely based on the experience of working with similar types of triaxial cells in the laboratory for over 15 years.

A threaded hole at the bottom of the piston holder may be included to facilitate the mounting of the cell on the rotation table/stage (as seen in figure 7(b)).

Note that with appropriate instrumentation, such as a suitable portable linear variable differential transformer to measure axial displacement and connection to a more sophisticated servo-controlled hydraulic system, the test setup can be used for triaxial tests in the laboratory. However, a detailed discussion of such an adaptation is beyond the scope of this paper, which focuses on the use of this test setup in beamline experiments.

\section{Functionality of the proposed triaxial cell in beamlines}

The triaxial test setup has been used to image fractures within various rocks at two beamlines: (a) at IMAT, STFC-ISIS facility, UK $[25,26]$; and (b) at the NIST NCNR, where a triaxial cell (with suitable wall thickness) was used in the NeXT beamline [27]. The following sections discuss the performance of the triaxial cells in these beamlines.

\subsection{IMAT beamline, ISIS facility, UK}

Figure 7 depicts the positioning of the cell on the IMAT beamline, ISIS facility, UK. The cell was $15 \mathrm{~cm}$ in front of the detector. The position of the cell with respect to the detector was adjusted using a laser mounted near the entrance of the beam in the experiment hall. An elbow connector, shown in 


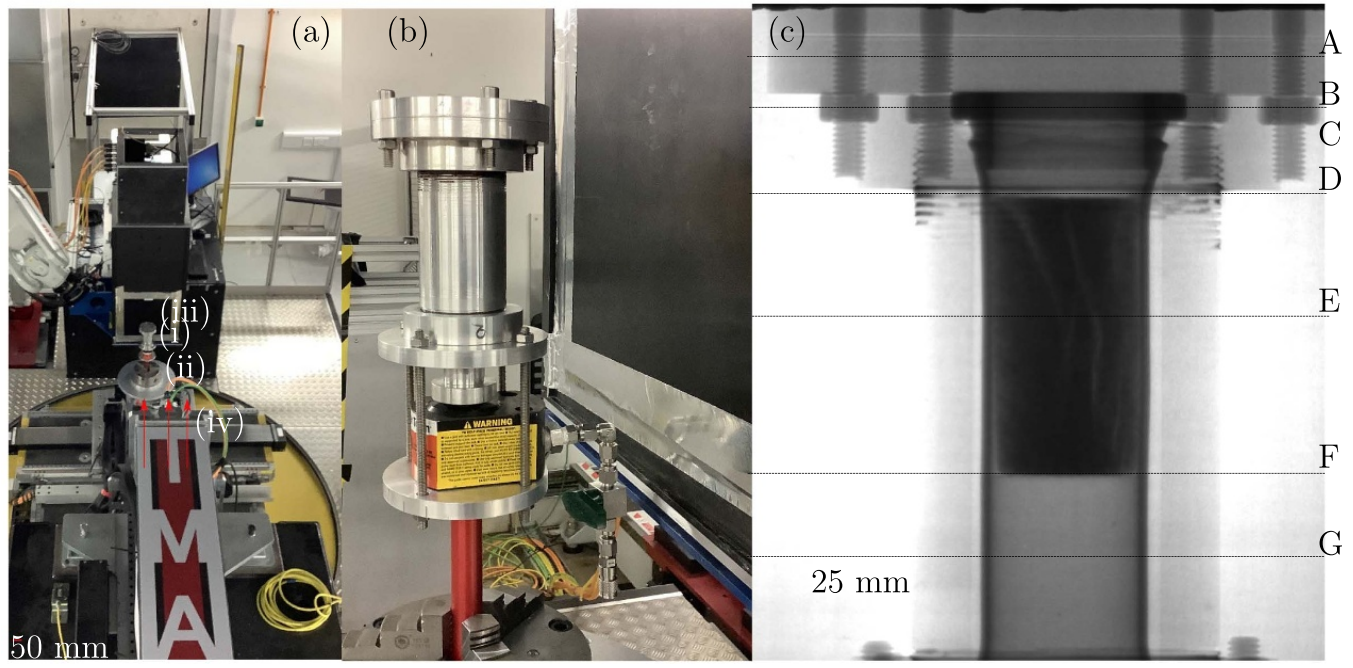

Figure 7. (a) Triaxial cell mounted on IMAT, ISIS facility: (i) cell, (ii) stage, (iii) detector and (iv) direction of the beam. (b) Close up of the cell with ancillary fittings to contain the axial load on the sample. (c) Neutron radiogram of the cell containing a Loch Aline rock sample of diameter $25 \mathrm{~mm}$.

figure 7(b), was used to minimize the distance the triaxial cell was positioned in front of the detector and enabled the triaxial cell to be isolated once axial stress was applied. The configuration of the elbow connector comprised a two-way valve and a Swagelok Miniature Quick-Connect connector, which enabled isolation of cell while maintaining axial stress. Figure 7(c) depicts one of the radiograms obtained for the water-saturated rock sample-a rock extremely rich in silicon from the side of Loch Aline in North West Argyll in Scotland [28]. Initial trials to image dry rock were unsuccessful due to very low attenuation of neutrons when passed through silicon-rich rock. It can be noted from figure 7(c) that a clear outline of the fractures appears to have propagated due to the application of the load. The voxel resolution obtained on IMAT was $\approx 120 \mu \mathrm{m}$.

Figure 8 depicts the variation of attenuation, $I / I_{\mathrm{o}}$, along the sections of the triaxial cell highlighted in figure 7 (c) with $\mathrm{A}$ through to $\mathrm{G}$. The reference $r=0 \mathrm{~mm}$ refers to the center of the triaxial cell. The following observations were made:

- Along A in figure 7, at $r=-40 \mathrm{~mm}$, the $I / I_{\mathrm{o}}=0.38$ was measured from the beamline experiments, which was due to the high tensile strength of bolts of diameter $6 \mathrm{~mm}$. With the density of material taken as $7.9 \mathrm{~g} \mathrm{~cm}^{-3}$, the mass attenuation coefficient, $\mu / \rho$ was found to be $0.2 \mathrm{~cm}^{2} \mathrm{~g}^{-1}$, which is in agreement with those reported in the literature for $\mathrm{Fe}[22]$.

- For the section indicated by line A and $r=0 \mathrm{~mm}$, the attenuation of the beam is due to aluminum alone traveling through the $80 \mathrm{~mm}$ diameter of the top platen. Using the density of $\mathrm{Al}$ as $2.7 \mathrm{~g} \mathrm{~cm}^{-3}, \mu / \rho$ was found to be $0.047 \mathrm{~cm}^{2} \mathrm{~g}^{-1}$, which is comparable to results reported for $\mathrm{Al}$ in [22].

- The $I / I_{\mathrm{o}}$ measured along sections B, C and D can be used to confirm the presence of aluminum or iron (due to the bolts).
- At $r=0 \mathrm{~mm}$ in section $\mathrm{E}$, the $I / I_{\mathrm{O}}=0.09$ is a combination of beam attenuation due to $\mathrm{Al}$ in the cell body, $\mathrm{Si}$ in the grain and $\mathrm{H}$ in the pore space of the rock sample and in the Viton sleeve.

- At $r=0 \mathrm{~mm}$ in section $\mathrm{G}$, the $I / I_{\mathrm{o}}=0.448$, which is predominantly due to $\mathrm{Al}$ and $\mathrm{H}$ in the Viton sleeve.

- Although $\mathrm{F}$ is taken at the interface between rock and the $\mathrm{Al}$ of the loading side platen, the $I / I_{0}=0.236$ at $r=0 \mathrm{~mm}$ is less than those observed at $\mathrm{G}$ but greater than the $\mathrm{H}$ dominated attenuation at $\mathrm{E}$. It suggests that the attenuation at $r=0$ $\mathrm{mm}$ in section $\mathrm{F}$ is due to a combination of aluminium in the triaxial cell, hydrogen in the rock and Viton sleeve and silicon in rocks.

- The gradual change in attenuation at a few locations along all the sections can be noted, which is attributed to the combination of material and its thickness along the direction of the passing beam.

In conclusion, it was noted that the design of the triaxial cell is suitable for its intended purpose of using it in a beamline for identification of specific characteristics of geomaterials subjected to triaxial state of stress and the attenuation of the beam at various spatial locations is largely as expected from the materials used in its manufacture.

\subsection{BT2, NIST NCNR, NIST, MD, USA}

Experiments were conducted at the BT2 beamline at NIST NCNR in Gaithersburg, MD, USA. The BT2 facility is equipped with an X-ray imaging facility in addition to a neutron-imaging facility, thereby enabling the collection of X-ray and neutron images simultaneously [27]. In BT2, due to the constraint of $\mathrm{x}$-ray attenuation, the wall thickness needed to be reduced. The triaxial cell was therefore modified to remove the material on the cylindrical part of the cell body in order to 


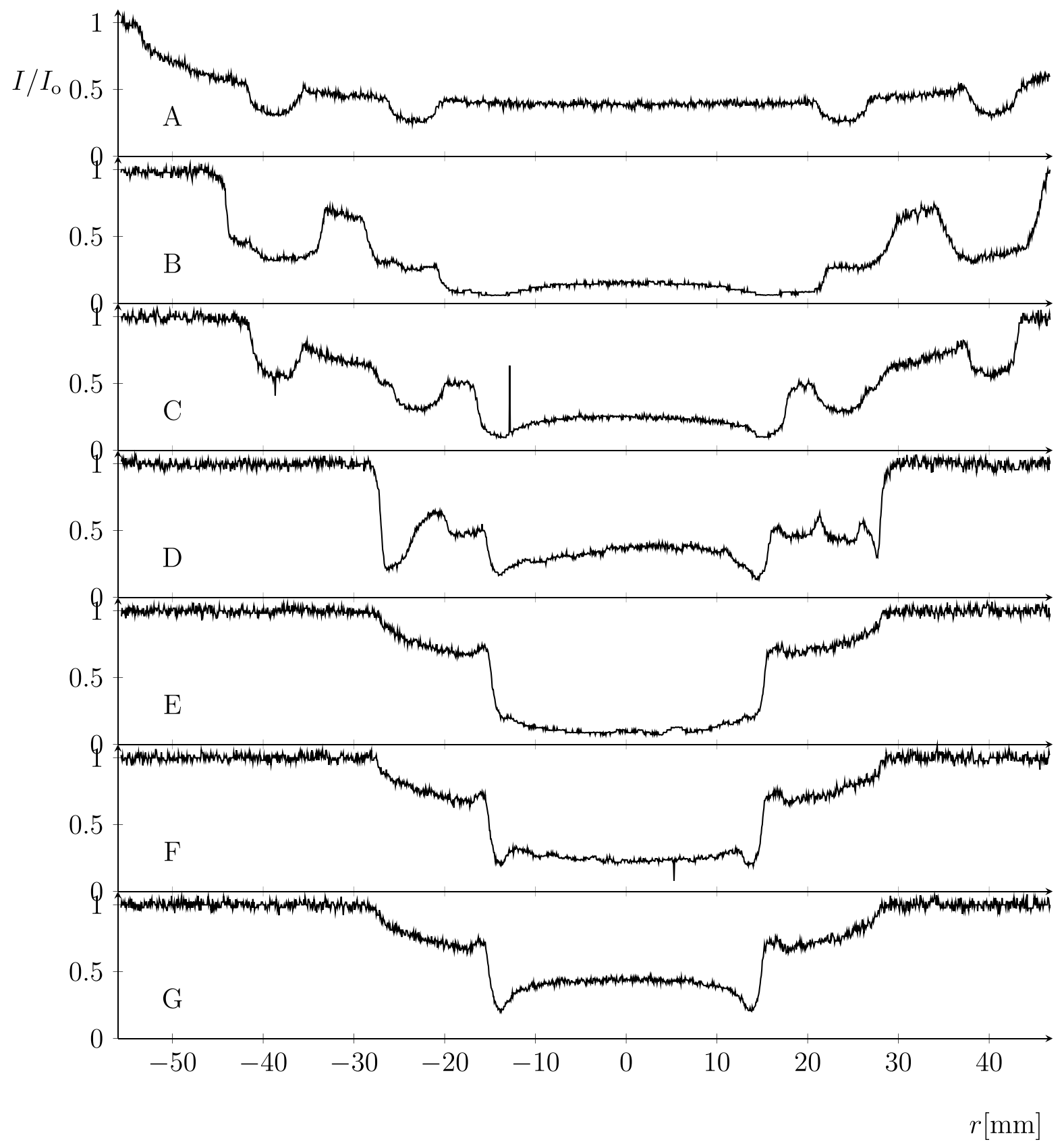

Figure 8. Variation of $I / I_{\mathrm{o}}$ along selected sections of the triaxial cell.

have a wall thickness of $2 \mathrm{~mm}$. Figure 9(a) depicts the modified cell with reduced wall thickness. Structural analysis of the 3D model was conducted to ensure that the design was safe under operating loads.

Figures 9(b) and (c) depict the x-ray and neutron radiograms of Locharbriggs rock sample-a high porosity quartz rich $(88 \%)$ red standstone of Permian origin, sourced from a quarry near Dumfries in south-west of Scotland [29]. The high neutron flux at BT2 and relatively low silicon content of Locharbriggs sandstone enabled imaging experiments to be carried out without saturating it with water.

The obtained voxel resolution for neutron imaging was $\approx 30 \mu \mathrm{m}$ and for that of $\mathrm{x}$-ray was $\approx 30 \mu \mathrm{m}$. It is to be noted that the Viton sleeve was not used in these experiments.
Figures 10 and 11 depict the attenuated neutron and x-ray beams through the triaxial cell. The following observations were made:

- Section A in figures 9(b) and (c) is composed mainly of aluminium. At $r=0 \mathrm{~mm}$, the center of the triaxial cell, $I / I_{\mathrm{o}}=0.65$ and therefore $\mu / \rho=0.032 \mathrm{~cm}^{2} \mathrm{~g}^{-1}$, which is lower than those reported in [22]. However, for X-rays the attenuation ratio at the same location, $I / I_{\mathrm{o}}=0.035$ and $\mu / \rho=0.248 \mathrm{~cm}^{2} \mathrm{~g}^{-1}$, greater than those interpolated from the data from [23].

- For $r=0 \mathrm{~mm}$ in section $\mathrm{C}$, which primarily consists of dry rock, i.e. silicon, $I / I_{\mathrm{o}}=0.556$ for neutron beam and $I / I_{\mathrm{o}}=0.1$ for $\mathrm{x}$-ray. The attenuation is mainly due to the 


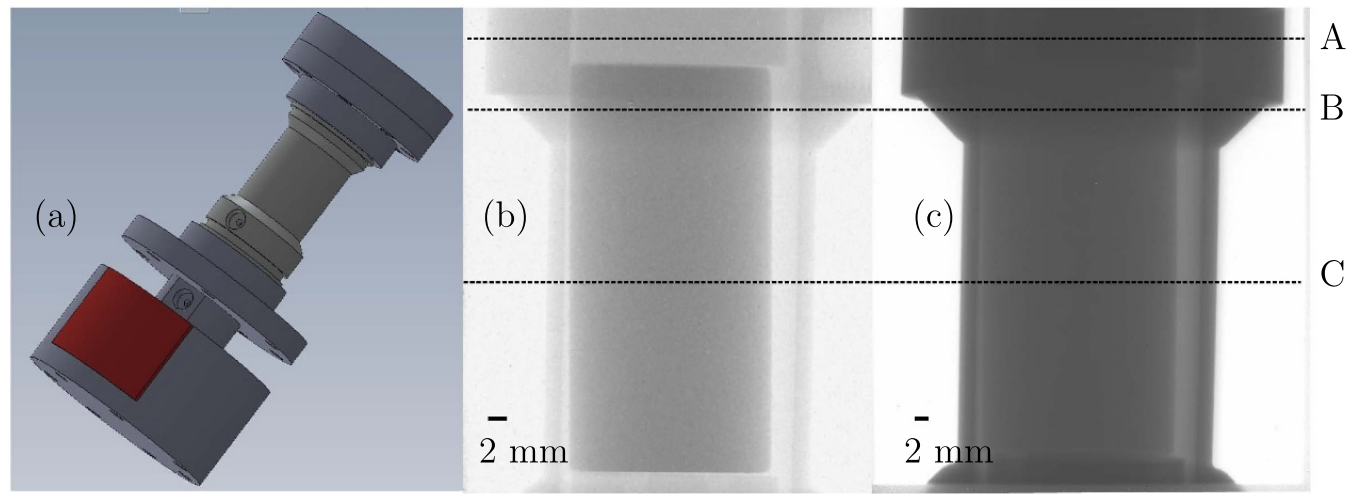

Figure 9. Cell in beamline at BT2, NCNR facility. (a) 3D image of modified design of triaxial cell, (b) neutron and (c) x-ray radiograms of Locharbriggs sandstone.

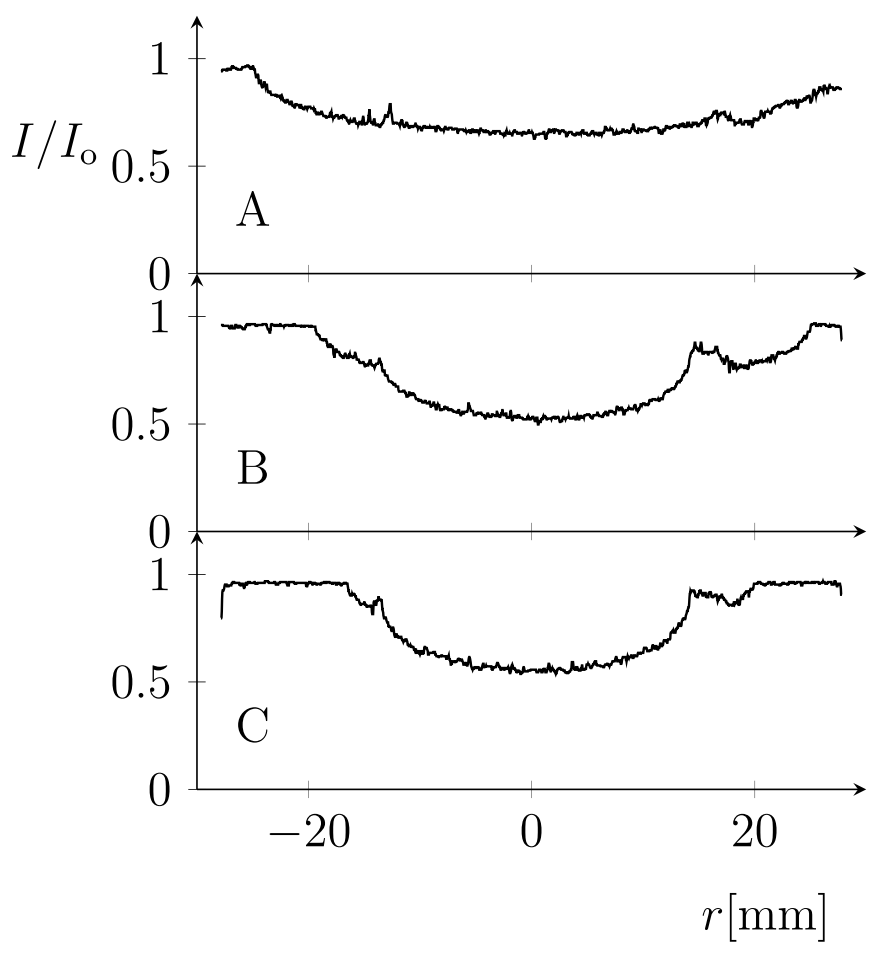

Figure 10. Attenuation of the neutron beam through the triaxial cell at BT2, NCNR.

silicon in the rocks with contribution of aluminium and taking the density of silicon to be $2.33 \mathrm{~g} \mathrm{~cm}^{-3}$, the $\mu / \rho=0.049$ $\mathrm{cm}^{2} \mathrm{~g}^{-1}$ for neutrons and $\mu / \rho=0.040 \mathrm{~cm}^{2} \mathrm{~g}^{-1}$ for x-rays, which is slightly lower than those reported by [23], with the variation attributed to the presence of aluminium and other metallic inclusions in the main body of the triaxial cell.

\subsection{Limitations of the current triaxial cell design and suggestions for improvement}

The following are some of the identified limitations of the current design.

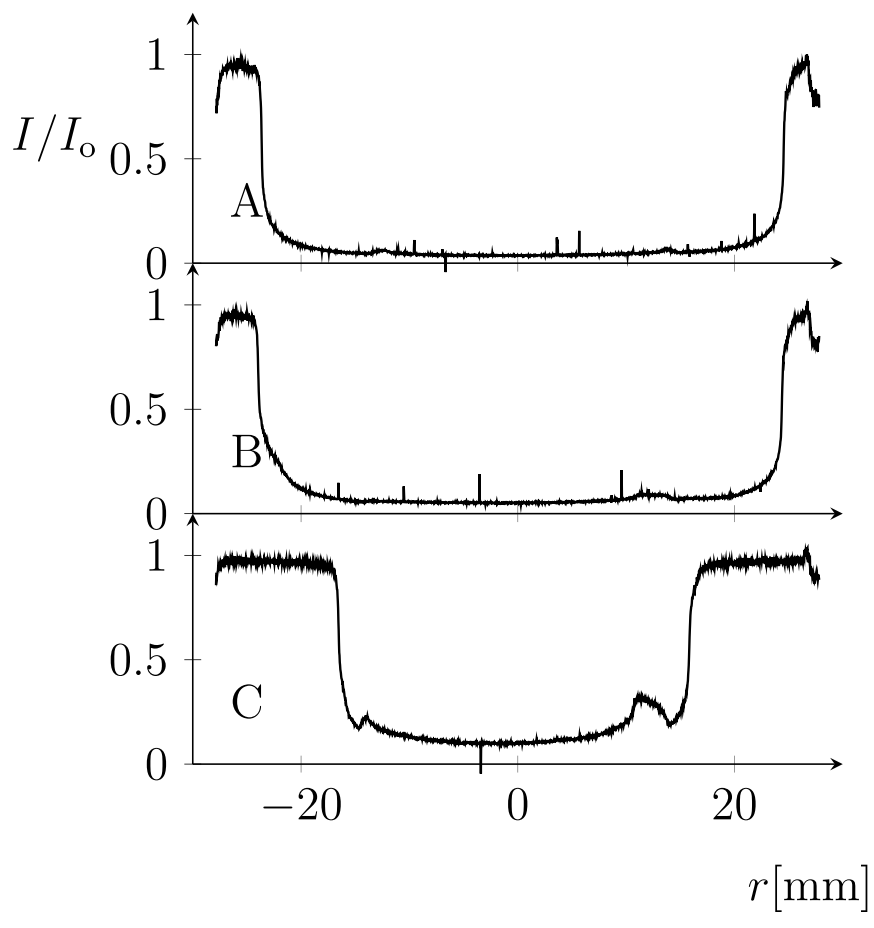

Figure 11. Attenuation of the $\mathrm{x}$-ray beam through the triaxial cell at BT2, NCNR.

- The mechanical response of rock is sensitive to the rate of strain used in the triaxial test. The International Society of Rock Mechanics recommends a strain rate of 20 millistrain per hour. However, the current test setup only enables the application of instantaneous load. One suggestion would be to replace the manual hydraulic pump with a pressure controller that can enable application of axial displacement while maintaining a constant rate of strain. This would enable reproduction of identical laboratory triaxial conditions in the beamlines.

- The continued dilation of rock due to the increase in applied axial load would increase the radial displacement, which would in turn increase the pressure in the confining fluid chamber. Therefore, a further improvement would be to 
connect the confining pressure to a device that could control the confining stress during the experiment, for instance, a pressure controller. However, the plumbing needs to be carefully considered as it would be a major limiting factor for most beamlines that have rotating stages. One suggestion would be to investigate the use of multi-channel hydraulic or pneumatic rotary unions that would allow the rotation of the stage while maintaining pressure connectivity between the confining pressure chamber and the controller.

\section{Conclusions}

A portable triaxial rock sample holder design is presented, which can be used to image flow and deformation under a triaxial state of stress. The design is versatile and can be modified to suit different beamlines that have stationary sources while the triaxial cell is rotated from $0^{\circ}$ to $180^{\circ}$ or $360^{\circ}$. The current design ensures that the cell is isolated under stress for imaging, thereby eliminating long flow lines which may not be conducive in some experimental scenarios. The triaxial cell was used for imaging the deformation characteristics and fracture propagation in clastic rocks at two beamlines. The $\mu / \rho$ computed for aluminium, silicon and iron were found to be in close agreement with those reported in the literature.

\section{Data availability statement}

All data that support the findings of this study are included within the article (and any supplementary files).

\section{Acknowledgments}

The development of the cell was supported by the Research and Teaching Excellence Fund of the School of Engineering, University of Aberdeen. Experiments at BT2, NCNR were supported by UK Engineering and Physical Sciences Research Council Grant No. EP/N021665/1, NIST and the Physical Measurement Laboratory. Experiments at IMAT were supported by the UK STFC, Experiment Number: 1910331 (https://doi.org/10.5286/ISIS.E.RB1910331).

\section{ORCID iDs}

Amer Syed (D) https://orcid.org/0000-0002-3654-3950 Yukie Tanino (D) https://orcid.org/0000-0002-5766-0515 Genoveva Burca (D) https://orcid.org/0000-0001-6867-9628

\section{References}

[1] Kardjilov N, Hilger A, Manke I, Strobl M, Dawson M and Banhart J 2009 New trends in neutron imaging $\mathrm{Nucl}$. Instrum. Methods Phys. Res. A 605 13-5

[2] Kumar J, Attridge A, Wood P K C and Williams M A 2011 Analysis of the effect of cone-beam geometry and test object configuration on the measurement accuracy of a computed tomography scanner used for dimensional measurement Meas. Sci. Technol. 22035105

[3] Lee J S, Weon B M and Je J H 2013 X-ray phase-contrast imaging of dynamics of complex fluids J. Phys. D: Appl. Phys. 46494006

[4] Bauer D, Chaves H and Arcoumanis C 2012 Measurements of void fraction distribution in cavitating pipe flow using x-ray CT Meas. Sci. Technol. 23055302

[5] Richards W J, Gibbons M R and Shields K C 2004 Neutron tomography developments and applications Appl. Radiat. Isot. 61 551-9

[6] Dierick M, Vlassenbroeck J, Masschaele B, Cnudde V, Van Hoorebeke L and Hillenback A 2005 High-speed neutron tomorgaphy of dynamic processes Nucl. Instrum. Methods Phys. Res. A 542 296-301

[7] Vontobel P, Lehman E and Carlson W D 2005 Comparison of $\mathrm{X}$-ray and neutron tomography investigations of geological materials IEEE Trans. Nucl. Sci. 52 338-41

[8] Wilding M, Lesher C E and Shields K 2005 Applications of neutron computed tomography in the geosciences Nucl. Instrum. Methods Phys. Res. A 542 290-5

[9] Winkler B, Kahle A and Hennion B 2006 Neutron radiography of rocks and melts Physica B 385-386 933-4

[10] Iglauer S, Paluszny A, Pentland C and Blunt M 2011 Residual $\mathrm{CO}_{2}$ imaged with x-ray micro-tomography Geophys. Res. Lett. 38 L21403

[11] Perfect E, Cheng C-L, Kang M, Bilheux H Z, LaManna J M, Gragg M J and Wright D M 2014 Neutron imaging of hydrogen-rich fluids in geomaterials and engineered porous media: a review Earth Sci. Rev. 129 120-35

[12] Degueldre C, Pleinert H, Maguire P, Lehman E, Missimer J, Hammer J, Leenders K, Boeck H and Townsend D 1996 Porosity and pathway determination in crystalline rock by positron emission tomography and neutron radiography Earth Planet. Sci. Lett. 140 213-25

[13] Hellmuth K H, Siitari-Kauppi M, Klobes P, Meyer K and Goebbels J 1999 Imaging and analyzing rock porosity by autoradiography and $\mathrm{Hg}$-porosimetry/x-ray computer tomography-applications Phys. Chem. Earth A 24 569-73

[14] Behnsen J, Blake O O, Cernik R J and Withers P J 2014 Identifying microcracks in multi-phase crystalline rocks by $\mathrm{x}$-ray CT iCT Conference

[15] Christe P, Bernasconi M, Vontobel P, Turberg P and Parriaux A 2007 Three-dimensional petrographical investigations on borehole rock samples: a comparison between x-ray computed- and neutron tomography Acta Geotech. 2 269-79

[16] Hoek E and Franklin J A 1968 Simple triaxial cell for field or laboratory testing of rock Trans. Inst. Miner. Metall. 77 A22-6

[17] Fu K K, Yang M C and Wood K L 2016 Design principles: literature, review, analysis and future directions ASME J. Mech. Des. 138 101103-1-13

[18] Mohedas I, Daly S R and Sienko K H 2015 Requirements development: approaches and behaviors of novice designers ASME J. Mech. Des. 137 071407-1-10

[19] Fender J, Graff L, Harbrecht H and Zimmermann M 2014 Identifying key parameters for design improvement in high-dimensional systems with uncertainity ASME J. Mech. Des. 136 041007-1-10

[20] Kraemer P and Weckenmann A 2010 Multi-energy image stack fusion in computed tomography Meas. Sci. Technol. 21045105

[21] Banhart J, Borbély A, Dzieciol K, Garcia-Moreno F, Manke I, Kardjilov N, Kaysser-Pyzalla A, Strobl M and Treimer W 2010 X-ray and neutron imaging - complementary techniques for materials science and engineering IJMR 101 1069-79 
[22] Berger H 1971 Neutron radiography Annu. Rev. Nucl. Sci. $21335-64$

[23] Hubbell J H and Seltzer S M 2004 NIST Standard Reference Database 126: x-ray mass attenuation coefficients (https://www.nist.gov/pml/x-ray-mass-attenuationcoefficients) (Accessed 20 December 2020)

[24] Fusseis D, Steeb H, Xiao X, Zhu W, Butler I B, Elphick S and Maeder U 2014 A low-cost X-ray-transparent experimental cell for synchrotron-based x-ray microtromography studies under geological reservoir conditions J. Synchrotron Radiat. $21251-3$

[25] Burca G, Kockelmann W, James J A and Fitzpatrick M E 2013 Modeling of an imaging beamline at the ISIS pulsed neutron source J. Instrum. 8 P10001
[26] Kockelmann W et al 2015 Status of the neutron imaging and diffraction instrument IMAT Phys. Proc. 69 71-8

[27] LaManna J M, Hussey D S, Baltic E and Jacobson D L 2017 Neutron and x-ray tomography (NeXT) system for simultaneous, dual modality tomography Rev. Sci. Instrum. 88113702

[28] Humphries D W 1961 The upper Cretaceous white sandstone of Loch Aline, Argyll, Scotland Proc. Yorks. Geol. Soc. 33 47-76

[29] Ojala I O, Ngwenya B T, Main I G and Elphick S C 2003 Correlation of microseismic and chemical properties of brittle deformation in Locharbriggs sandstone J. Geophys. Res. Solid Earth 1082268 